\title{
Increasing Farmers' Access to Aquaculture Extension Services: Lessons from Central and Northern Uganda
}

\author{
Gertrude Atukunda $^{1 \& 2, *}$, Peter Atekyereza ${ }^{2}$, John K. Walakira ${ }^{3}$, Andrew E. State ${ }^{2}$ \\ ${ }^{1}$ National Fisheries Resources Research Institute, NARO. ${ }^{2}$ Department of Sociology and \\ Anthropology, Makerere University, ${ }^{3}$ Abi Zonal Agricultural Research Institute, NARO \\ *Corresponding author. @ getrude.atukunda@gmail.com
}

\begin{abstract}
This paper focuses on examining the modalities of extension service provision, and determining feasible approaches for increasing accessibility among fish farmers in Uganda. The paper draws on a cross-sectional study involving fish farming households and extension workers to determine access to extension services for improved farming practices. Quantitative data were collected from 246 households using a semi-structured questionnaire. Qualitative data were generated from Key Informant interviews with selected extension workers, officials in charge of extension planning District Fisheries Officers and Fish Farmer Group leaders. Focus Group Discussions were also conducted with fish farmers. The results indicated a significant association between socioeconomic characteristics of fish farmers and access to extension services. Size of land owned, income from pond fish and membership to fish-farmer groups were the significant factors $(\mathrm{P}<0.05)$. All the respondents reported pressing needs which required extension intervention. The respondents expressed the need to form effective farmer groups for the purpose of sharing knowledge, arriving at mutual agreement on scheduling extension activities and providing feedback to the extension workers. Specifically for the northern region, there is a need for the Fisheries Extension Officer to identify and respond to the extension needs of fish farmers through various means including ICTs. Identifying solutions to social, technical and institutional constraints in extension can increase access to services through constructive social interactions between farmers and extension agents. The article provides important lessons for practice and policy, and proposes a farmer-centred model, capable of facilitating increased access to aquaculture extension services in Uganda.
\end{abstract}

Keywords: Aquaculture, Extension services, Pond-fish farming, ICTs.

\section{Introduction}

Aquaculture is an important undertaking, and is a source of employment, food, nutrition and income. Globally, aquaculture is on the rise with Asia as a leading producer, from 34.2 million tonnes in 1996 to 82.1 million tonnes in 2018. China is the world topmost producer with 47.5 million metric tonnes, a share of 57.9 per cent (FAO 2020a). Over the same period, the share of Africa has increased from 110 thousand tonnes to 2,195.9 million tonnes, and account for 
17 per cent of total global production. Egypt is the leading producer in Africa with 1.5 million tonnes (FAO 2020b). The next big producer in Africa is Nigeria, with 0.2 million tonnes (FAO 2007-2020), followed by Uganda with 0.1 million tonnes (FAO 2004-2020). These figures are however still low considering the targets set by various countries, such as Uganda, that aims at producing 1 million tonnes (MAAIF 2018). Amidst the lauded aquaculture growth of 7 per cent per annum since 1970 are environmental, technical and socio-economic challenges that need attention as a measure to meet the needs of the increasing population, particularly in Africa (FAO 2020b). Strategies that focus on access to improved aquaculture technologies and business skills are particularly important.

In Uganda, aquaculture was introduced in the 1950s. Production remained low, until around 2010 when exponential increase was noted from 95,000 tonnes (FAO 2010) to 118,051 tons in 2018 (MAAIF 2019, FAO 2020a, FAO 2020b). Uganda needs 829,200 tonnes of fish annually, considering the current estimated population of 40 million people (MAAIF 2019, UBOS 2019) to meet the increasing demand for fish. Aquaculture in Uganda involves rearing fish (fish farming) as part of other agricultural enterprises, and falls under the government overarching policy framework that governs agricultural production, the National Agriculture Policy of 2013 (MAAIF 2013). The agricultural sector has other policies specific to crops, livestock and fisheries production as well as agricultural extension services. Fish farming has been identified as a measure for addressing the growing deficit in fish supply (MAAIF 2018). Meeting the increasing demand for fish in Uganda requires removal of barriers that hinder increased aquaculture fish production by promoting active involvement of farmers in extension services and use of appropriate technologies for sustainable production.

Extension service provision involves interventions and activities that facilitate the access to, and proliferation of knowledge, information and technologies among farmers. This reflects the need to avail content necessary for augmenting the competence of the extension workers. Coverage of agricultural extension services in Uganda is low, and estimated at 22 per cent, with a ratio of extension staff to farmers at 1: 15000 (MAAIF 2016b). A number of reasons, account for this scenario, including inadequate budgetary allocation and ineffective extension approaches (MAAIF 2016b). The approach to addressing these barriers would involve all relevant actors in the process of re-examining the planning and delivery of extension services at national and local government levels. Specific to aquaculture, a suitable model identified by fish farmers and relevant stakeholders is necessary for increasing access to extension services, and ultimately increasing fish productivity and profitability. This course of action is in line with Uganda's aspiration to transform the agricultural sector from subsistence to commercial agriculture (Government of Uganda 2020, National Planning Authority (NPA) 2020).

Recent research has focused on general aspects of extension in developing countries like Ghana and Nepal but information on efficient extension approaches in fish farming remains limited (Azumah et al., 2018, Suvedi et al., 2017, Adong et al., 2013). For instance, the use of Information and Communications Technology (ICT) in extension services is gaining tremendous attention in fish farming as studies in Egypt and Nigeria, the leading African aquaculture producing countries show (Ejiogu-Okereke et al., 2016, Kassem et al., 2019). Furthermore, research on agricultural extension tends to focus on high value agricultural crops, such as rice (Rugema et al., 2018), and coffee, beans maize and cassava (Ndibongo-Traub and Jayne 2018). Yet aquaculture products are equally important for food security, and contribute to livelihoods of farmers. Moreover, there is a limit to which some of the results can be generalised for fish farming given its uniqueness in terms of widely dispersed famers, hence requiring extension methods that ensure access to information and other services. 
A range of factors that influence farmers' participation and access to extension services such as farm size and membership to groups, (Abdallah and Abdul-Rahaman 2016, Suvedi et al., 2017). Specific to aquaculture, only few studies focus on extension services provision in the East African region and Uganda. Obiero et al., (2019) found a positive relationship between farmer characteristics and adoption of technologies with 28 per cent high adopters. Atukunda et al., (2018) found 48 per cent of fish farmers receiving the services needed to improve pond fish production. Besides socio-economic factors, scholars note the influence of institutionrelated factors on extension service provision. From an institutional perspective, the extension approach used influence access to services. For example, (Wellard et al., 2013, FAO 2017) highlight participatory approaches as appropriate for increasing access to extension services. In general, literature shows that greater efficiency and effectiveness can be achieved through use of different extension methods such as face to face interactions with farmers, and audio-visual media (Mpiima et al., 2019, Norton, and Alwang 2020). Whereas literature shows resource limitations and extension personnel's bias towards working with farmers of high socioeconomic standing (Rogers 2003), participatory approaches can increase social encounters between extension workers and farmer group members. Moreover, (Ekou and Alungat 2015) observed that merely intensifying the extension service and increasing the number of extension officers may be ineffective if active participation of the farmers themselves is not enlisted. Moreover, membership to farmer groups is generally low (16\%) as Adong et al., (2013), Mwaura (2014) observed, and called for policy intervention to guide formation of farmer groups.

As a means of increasing benefits from group approaches, (David and Asamoah 2011) suggests combining ICT methods such as video viewing clubs as well as mobile phone usage (Martin and Abbott 2011) to access extension messages. Studies on effective extension approaches in aquaculture, (Kumaran et al., 2012, Ejiogu-Okereke et al., 2016) show how extension personnel can use mobile phones to coordinate farmers' clusters meetings and ensure that audio-visuals and extension literature is effectively used. Moreover, studies have shown that farmer leaders working under the Village Enterprise Agent model can effectively engage in extension service provision, including use of mobile telephony (Mugabi et al., 2018). Concerning the efficiency of the different mass media channels, Norton and Alwang (2020) observe that although mass media help extension agents to reach large numbers of farmers simultaneously, there is little opportunity for these farmers to interact among themselves or to provide feedback to the extension agents. To overcome this limitation, Kassem et al., (2019) suggests use of mobile-based extension services as they enable sharing information and linking farmers with other actors in the agricultural value chain. The Uganda Communications Commission (UCC 2019) reports limited knowledge and low usage of ICTs in agricultural extension. As Freeman and Mubichi (2017) observe, effective usage of ICTs requires a thorough understanding of the types of ICTs used and information accessed by farmers so as to identify critical niches for improving interventions.

The critical issue of concern for increasing access to extension services is financial resources to cover cost of travel, stationery and other materials used during activities such as demonstrations and training. Faure et al., (2012) identify the institutional environment, the necessary structures, the actors and the approaches as major aspects in agricultural extension service provision. While an understanding of these aspects is important, the lack of sufficient resources to fund implementation of relevant actions is a limiting factor. For example, following reforms and implementation of participatory agricultural extension system, evaluation studies conducted in Uganda, Kenya and Ethiopia (AfranaaKwapong and Nkonya 2015, Muyanga and Jayne 2008, Taye 2013), revealed budget limitations as the main challenges to effect desired change. Similarly for the farmers, financial shortages may limit the extent to which extension 
messages can be applied to improve farm productivity (Hailemichael and Haug 2020). Farmers need appropriate advice and technologies to operate productive and profitable enterprises.

Although studies highlight limited access and poor quality fish production inputs such as fingerlings and feeds (Tibihika 2014, Hyuha et al., 2011), the major concern for fish farmers is access to extension services needed to address the constraints they encounter (Atukunda et al., 2018, Kasozi et al., (2014). Moreover, the fish farmers would still require technical advice on effective management and application of the inputs, because providing technical advice to farmers is a function of extension that involves the farmer, the extension worker and the institutional operating environment (Aanyu et al., 2020). Basing on perspectives of extension workers and fish farmers, the study sought to establish lessons for increasing access to extension services. The inquiry into extension agent-farmer interactions was informed by literature that portrays extension work as biased towards farmers with particular characteristics and often interconnected through interpersonal networks (Rogers 2003:383, Vanclay 2004, Long 2001, Gido et al., 2014). What the literature overlooks is examining the role of fish farmers in increasing access to extension services, and the feasible mechanisms to ensure efficient farmerextension worker interactions.

The overall aim of the paper therefore is to examine gaps in aquaculture extension service provision and propose mechanisms of increasing access to extension services. The underlying assumption was that although farmers essentially appear at the receiving end, their agency as participants in extension plays a crucial role in promoting increased access to extension services. The paper focuses on individual farmer and household level characteristics, including the nature of engagement in fish farming and extension service provision. Specifically, the first objective of this article was to establish the relationship between the socio-economic characteristics of fish farmers and provision of extension services. Understanding the relationships enables cautious execution of extension activities in view of farmer-related characteristics. The second objective was to assess the role of farmers in extension service provision, capable of increasing access to extension services. The authors draw from Long's Actor-oriented perspective that envisage farmers as active participants whose knowledge, decisions and actions can increase access to extension services (Long 2001). Long's assertion points to the need to recognise the centrality of farmers in the design and implementation of extension interventions. The paper concludes with suggestions for increasing access to extension services, through usage of farmercentred extension model.

\section{Methodology}

The paper bases on results of a cross-sectional descriptive study carried out during 2015 and 2016. The study employed a descriptive survey design as a means to fill knowledge gaps on pond fish farming, with particular focus on access to extension services. The survey generated quantitative data about the demographic and socio-economic characteristics of respondents as well as access to extension services in fish farming. In addition, in-depth descriptive and interpretive inquiry was used as a follow-up to gather detailed qualitative information on respondents' opinions about the influence of institution-related factors in extension service provision. Hence, the study design enabled integration and complementarity of results (Bryman 2006, 2007, Creswell et al., 2011). To assess the influence of farmer-related factors, the hypothesis that there is no statistically significant relationship between the number of extension visits and the farmers' socio-economic characteristics was tested. Among the measures to ensure validity of the results, a twelve months recall period preceding the study was considered 
during interviews with respondents. The number of visits made by government extension workers over a twelve-month period preceding the interviews was used as an indicator of extension service provision. Similarly, the period was used as a reference point for collecting and analysing data on household incomes.

Given that pond fish farming districts are not located closely to each other, area sampling was used to aim at a big population of households. Purposive sampling was used to select the central and northern regions, and the respective districts. Bukomansimbi, Kalungu, Lwengo, Nasaka and Mpigi districts were selected in the central region while Alebtong, Kole and Lira were selected from the Northern region. The selection considered the existing intensity of fish farming as well as the income levels (UBOS 2011, MAAIF 2016c, MAAIF 2018). Understanding the relationship between respondents' socio-economic variables and access to extension services in the two regions was among important considerations during the study. Overall, the criteria used to select the regions and districts aimed at providing results beyond one region for purposes of complementarity and comparison. The study population comprised of households engaged in fish farming, with the household as the unit of analysis. Given that fish farmers are widely dispersed, area sampling was judged appropriate to select study areas from the two regions. Area sampling is appropriate when large geographic units are required to select the study area (Ahuja 2011:174, Kothari and Garg 2014). Using a large study area enabled obtaining a large population of the widely dispersed fish farming households from which to draw a representative sample for the survey. The sample was drawn statistically in order to ensure all elements of the population got equal chance of being included. The sample size was calculated using a formula by Kish (1965), and generated 246 fish farming households, of which $15(6.1 \%)$ were female-headed. In total, 100 and 146 households were from the central northern regions respectively.

Data collection methods involved document reviews, interviews and Focus Group Discussions (FGDs). Document review focused on analysing extension approaches used by various government projects and policy documents on agriculture, fisheries and extension. A structured questionnaire was used to collect quantitative data through interviews with fish farming household heads to establish the relationships between farmers' socio-economic characteristics and extension service provision. In addition, 27 Key Informant Interviews (KIIs) were conducted with a cross-section of selected relevant stakeholders in extension service provision such as MAAIF officials, media, Leaders of fish farmer associations and Aquaculture scientists. Eight FGDs, were conducted with selected participants in separate groups for women and men, each comprising six to ten participants. Information was captured using a voice recorder and note taking. KIIs and FGDs generated qualitative data for in-depth understanding of the issues indicated in the research questions. The discussions explored aspects such as patterns of social interaction among fish farmers and extension workers, and mechanisms for improving extension service provision.

Quantitative data were analysed using the Statistical Package for the Social Sciences (SPSS) version 22. The analysis generated descriptive statistics on the demographic and socioeconomic characteristics of fish farmers and institutional factors related to extension service provision. For qualitative data, thematic analysis was used to code data segments and draw themes that enabled detailed in-depth description of farmer characteristics and access to extension services. Besides exploring associations between major themes under inquiry, results from qualitative data analysis helped to identify direct quotes that provided detailed explanation of the results. 


\section{Results and Discussion}

\section{Fish farmer characteristics and extension service provision}

This study assessed access to extension services for households engaged in pond fish farming. The majority of the households were headed by males (93.1\%), of whom 83 per cent were married. The mean age of the household head was 53 years. More than half of the household heads $(56.5 \%)$ had a minimum of secondary school education, $39.4 \%$ had primary level while $4.1 \%$ had no formal school education. With regard to ownership of transport means by respondents, 16.3 per cent owned vehicles, 32.5 per cent owned motor-cycles, while 76.0 owned bicycles. The mean annual income for the households was US $\$ 1520$ (1USD=UGX3539 in 2016). Computation of income from fish showed a total of UGX 174.4 million with a mean of US $\$ 503$. Average land ownership was 5.3 hectares and was above the national average of 1.3 hectares (UBOS 2020) implying a higher socio-economic standing of pond fish farmers.

Across the two regions in this study (central and northern), there were no statistically significant differences in the demographic characteristics such as sex, age, and education of respondents. Statistically significant differences were noted in some of the socio-economic characteristics of the respondents. Notably, the results indicated a statistically significant difference $(\mathrm{P}<0.05)$ in vehicle ownership $(27.0 \%$ respondents in central region, compared to $8.9 \%$ respondents in northern region). Similarly, the study found a statistically significant difference $(\mathrm{P}<0.05)$ in bicycle ownership, with more respondents in the northern region (88.4\%) compared to 58.0 per cent for the central region. The estimated mean total household income in the year preceding the study was UGX5.3million. In the central region, results indicated that the estimated mean total household income was UGX7.6 million shillings, while UGX3.8 was for the northern region. These results indicate a statistically significant difference $(\mathrm{P}<0.05)$ in annual household income by the respondents in central and northern regions. Regarding income from fish, the study found that 92 per cent of the respondents in central region, and 88 per cent in northern region earned income from fish in 12 months preceding the study. The estimated annual income from fish varied across the regions, with a mean of UGX 860,000 in central region and UGX 447,400 in the northern region. These results depict a statistically significant difference $(\mathrm{P}<0.05)$ in income from fish in the two regions. Similarly, the total pond area operated by household in the two regions varied. In the central, the mean total pond area was $30672 \mathrm{~m}^{2}$, while $880 \mathrm{~m}^{2}$ was for the northern region, indicating a statistically significant difference $(\mathrm{P}<0.05)$. The results from central region point to the need for extension workers in the northern region to advise fish farmers about increasing the acreage of fish ponds, and to apply the best fish pond management practices.

In terms of access to extension services, the farmers (48.4\%) mainly accessed extension services through farm visits by government fisheries extension staff. Farmers $(39.8 \%)$ were the second major actors providing extension services to fellow farmers. During farm visits, farmers received technical advice and demonstration of specific farming activities such as pond construction, general care for fish to ensure good growth and fish harvesting. Though preferred for their demonstrated effectiveness in increasing farmer-participation (FAO 2019), and adoption of innovations (Ali-Olubandwa et al., 2011), farm visits are costly in terms of time and transport to individual farms, and ultimately inefficient in terms of achieving wider coverage of farmers. Moreover, visits to individual farms miss the opportunity to tap the power of social networks that can promote shared learning and adoption of good practices. Challenges associated with incorporating farm visits in group approaches can be overcome by bringing together farmers with common needs to learn from each other. Furthermore, using this 
approach can reduce costs of travel to perform a similar activity at different farms, while at the same time promoting social interaction.

Besides face-face contacts with farmers, mass media was used to provide extension services to respondents. Radio was the most predominant mass media method though to a small extent covering 47 per cent of the fish farming households in the study area. Comparing the central and northern regions using a Chi-square test indicated a statistically significant difference $(\mathrm{P}<0.05)$ in obtaining fish farming information via radio. In the central region, 54 per cent households accessed information via radio compared to 41 per cent in the central region. The reason for this scenario is attributed to availability of a wide range of radio stations broadcasting farming programmes in the local language of the region namely Luganda. In the northern region, the study found that listenership to fish farming radio programmes was increased via efforts by some of the extension workers through seeking specific funding from NGOs and NAADS. The programmes however, were discontinued due to lack sustainable financing by the funding organisations and projects. The study did not find similar initiatives in central region on grounds of lack of alternative funding sources to supplement the meagre government budgets. A few respondents (17.9\%) accessed information on fish farming via television, with 37 per cent respondents in central, compared to 4.9 per cent in northern region, indicating a statistically significant difference $(\mathrm{P}<0.05)$. In-depth discussions during FGDs indicated that the driving factor to access radio and TV programmes was mainly cultural and particularly associated with the local language used in most of the programmes.

Further analysis using the Chi-square revealed relationships between socio-economic variables and access to extension services across the central and northern regions. Table 1 depicts results from the analysis of extension service provision and socio-economic characteristics of respondents. The number of visits made by government extension workers over a twelve month period was used as a proxy for extension service provision. Land ownership, income earned from pond fish and membership to fish farmer groups depicted statistically significant differences $(\mathrm{P}<0.05)$.

Table 1: Relationship between Extension Visits and Farmer Characteristics

\begin{tabular}{llll}
\hline Respondents' socio-economic characteristics & $\chi^{2}$ & df & P-value \\
\hline Age & 13.784 & 12 & 0.315 \\
Gender & 0.875 & 2 & 0.928 \\
Education & 14.682 & 20 & 0.794 \\
Land owned & 133.483 & 24 & $0.000^{*}$ \\
Income from pond fish & 37.941 & 24 & $0.035^{*}$ \\
Total pond area & 16.855 & 16 & 0.315 \\
Experience in fish farming & 8.959 & 16 & 0.915 \\
Membership to fish farmer group & 10.073 & 4 & $0.039^{*}$ \\
Region of residence & 3.277 & 1 & 0.070 \\
\hline
\end{tabular}

*Significant difference at 95\% confidence level

Results shown in Table 1 corroborate with views of the extension workers who reported that they were confronted with the need to fulfil their work obligations, while endeavouring to meet the needs of farmers, as one fisheries extension worker explained:

"My role is to promote fish farming in the district among farmers who have suitable land. I look out for farmers with large sizes of land that is suitable for expansion of fish farming. The farmer must also have keen interest to grow fish for profit since government policy emphasises increasing household incomes (KI respondent, Kole district). 
In addition, the fisheries officers mentioned that the main pull-factors towards visiting particular fish farmers are pro-activeness in seeking advice and applying the knowledge provided by extension workers.

Land ownership is an important factor in pond fish farming because of predominance of extensive production technologies. This implies that for farmers to increase fish production and productivity, the strategy used is to have more ponds depending on availability of land. The results therefore mean that the respondents with bigger land size were visited more frequently than their counterparts. These results reflect extension workers' bias towards farmers endowed with large land holding. Extension workers asserted that farmers owning large acreage are likely to construct more ponds thereby increasing fish production. Moreover, earning income from fish ponds demonstrates farmers' achievement of one of the goals for growing fish. From the view point of extension workers, such an achievement similarly portrays good job performance and an indicator of application of the advisory services provided.

Similarly, extension workers tend to associate themselves with farmers that earn income from fish ponds, and therefore paid frequent visits, particularly checking on the growth of fish and determining the right timing for harvesting fish for sale. The study established that only half of the respondents had earned income from their fish during the past twelve months preceding the field survey. Discussions with extension workers confirmed farmers' revelations and showed that income from fish ponds is a major outcome of the farmers' and extension workers efforts. For farmers, generating profit is the ultimate goal of fish farming that bestows a feeling of success. Similarly, extension workers reported a feeling of pride and satisfaction when the farmers harvest fish for sale and home consumption. These results imply that attainment of the objectives of fish farming at household level can increase access to extension services.

Social organisation in form of farmer groups is associated with extension service provision. Results of this study reveal that only 33.7 per cent of the respondents belonged to farmer groups, an indication that interventions to promote farmer groups have not achieved wide coverage of farmers. None the less, farmer groups remain a key point of entry into the life worlds of farmers, and a sphere for interfaces aimed at increased access to extension services. The study found that extension workers regarded farmer groups as a feasible means to facilitate dissemination of aquaculture information and technologies to fish farmers, particularly where government funds were insufficient to facilitate routine farm visits. Through working in groups, the fish farmers share information and perform certain activities such as marketing fish in a collective manner. Compared to individual farm visits, extension service provision through farmer groups was deemed more effective in terms of lower operational costs and coverage of a bigger number of farmers. Moreover, group extension approach fosters building social capital as well as maintaining contacts between farmers and extension workers.

Despite the advantages of group approaches, the study found that extension workers rarely conducted group trainings for fish farmers. In central region, 19 per cent of the respondents received training compared to 8.9 per cent in the northern region. The Chi-square test showed a statistically significant difference in the two regions. A factor that can explain the difference is the presence of fewer fisheries extension workers in northern region at the time of the study. Availability of extension workers in the communities is important for regular interactions to avail the services needed, and to receive feedback from farmers. Explaining the limited training activities, the extension workers mentioned unaffordable cost of facilitating farmers with transport for the return journey and providing refreshments during training. Government fisheries extension staff opt to train farmers in their respective groups as a measure of cutting costs involved in travelling to individual farms. One DFO explained: 
Farmers want to be visited individually at their farms so as to tackle specific needs, but this is not feasible given the small budgets allocated to the fisheries sub-sector. I opt to use the available budget to conduct group training to farmers at least once a year. I meet the farmers at a convenient venue identified by the fish farmers although some farmers would still have to travel long distances to the venue. (KI respondent, Kalungu district).

The explanation by the DFO implies that there are various methods for providing extension services to fish farmers. Depending on the resources available, the extension workers use their discretion to apply the most feasible methods. In such cases, using group approach is preferred for meeting the needs common to a group of farmers. This strategy enables the extension worker to efficiently utilise available small budgets to keep in contact with many farmers. Moreover, group-training provides opportunity for social interactions that can tackle extensionfarmer concerns.

The foregoing section has shown that biases exist in extension service provision, yet all the different categories of fish farmers need the services. The socio-economic characteristics of the fish farmers are among the important factors to understand in extension service provision. An understanding of the heterogeneity of fish farmers should be used to aim at fairness in extension service provision. Increasing fish pond production at community level is a factor of combined efforts by all fish farmers. Farmers should therefore actively participate in extension service provision, including demanding and seeking necessary advice as opposed to depending on a predetermined schedule and content of the extension workers. Institutional factors in provision of extension services

\section{The role of fish farmers in increasing access to extension services}

Besides content and the general management of extension service provision to fish farmers, an important consideration is the choice of approaches. Provision of extension services is a twoway communication approach involving the supply side (extension workers) and the demand side (farmers). While extension workers have the mandate to provide extension services to farmers, increasing access to the services can be achieved when farmers become active participants through expressing their needs.

Participation of farmers in extension services was assessed in view of their level of demand for services. Demand was measured by whether farmers expressed their needs through consultations made with extension worker. The results revealed low levels of consultations $(26.4 \%)$ with the various types of extension workers. For the respondents who did not make any consultations, the main reasons were high consultation fees charged, and associated transport costs to meet the extension workers (9.3\%), few extension workers $(5.7 \%)$, and uncertainties about receiving expected positive response from the extension workers $(5.3 \%)$. In instances where the farmers had failed to keep the fish ponds operational due to limited extension support, discouragement and loss of interest $(3.4 \%)$ were the deterrent reasons. Besides the negative experiences with demand for services, the majority of farmers who consulted felt satisfied $(26.9 \%)$ with the rejoinders provided.

On the other hand, the extension workers had a different view about farmers' low zeal to demand services. In-depth discussions revealed the complexities within the operating sociopolitical environment that impact on their role in extension service provision. The argument follows that as long as extension budget limitations continue to prevail, meeting the needs and demands remain a constraint. The extension workers cited lack of transport and low staff capacity in the districts as the key challenges in responding to on-farm advisory service needs. 
A related observation was that government policy provision to increase provision of extension services through private service providers remains unfulfilled (MAAIF 2016a). Furthermore, extension workers observed continued poorly planned and unsustainable supply of free inputs by government (particularly fish feeds and fingerlings) to farmers that distorts local level planning of extension service provision. According to the extension workers, the practice raises farmers' expectations for free services, creates a dependency syndrome and does not empower farmers to run their fish farming enterprise with a commercial bearing. For this reason, the farmers make unrealistic demands that are beyond the means of the extension workers. Such a state of affairs overlooks theoretical perspectives and undermines provision of opportunity to recognise the agency of farmers as active participants who process information and strategies in their dealings with various local actors as well as with outside institutions and personnel (Long 2001). The implication is that farmers should be given opportunity to determine beneficial interventions through engaging in dialogue with other relevant actors.

Much as the task of establishing farmer groups is the responsibility of extension workers, the initiative lies with the farmers followed with an expressed interest to organise. Groups are an important avenue for providing extension services and enabling access by farmers Kumaran et al., (2012). The results depicted absence of services for building social capital of fish farmers since only one per cent of respondents mentioned receiving information on forming groups or associations. Majority of respondents belonged to a particular prominent group in each region implying that other groups were less popular. For all the groups, it was the initiative of the fish farmers to form the groups. Often, the extension workers provided guidance on group formation and the necessary information for registration at the Sub-county and districts. The extension workers regarded farmer groups as a feasible means to facilitate dissemination of aquaculture information and technologies to fish farmers particularly where government funds were insufficient to conduct routine farm visits. These results substantiate findings on farmer groups as avenues for farmer mobilisation, organising training and dissemination of agricultural information among farmers (Lukuyu et al., 2012). For the case of fish farmers, working in groups can enable information sharing and performing activities such as marketing fish in a collective manner.

\section{ICT Usage in Extension Service Provision}

ICTs are increasingly becoming more available for use by different categories of people including farmers. ICTs can be regarded as part of the demand side of extension since the farmers have agency to use them. The study found that respondents owned ICT devices that can be used to communicate and access information needed for improving fish farming. The results indicated that 93.1 per cent households had mobile phones, 88.2 per cent had radios while 33.7 per cent had TVs. Apart from radio, ownership of mobile phones and TVs significantly varied across the two regions. The study found a statistically significant difference in ownership of mobile phones and TVs $(\mathrm{P}<0.05)$. More respondents in the central region owned mobile phones and TVs than their counterparts in the northern region.

The study results further indicated that 38 per cent of respondents in the two regions did not obtain fish farming information from any of the ICT sources, an indication of low utilisation. For mobile phones, usage was mainly individually driven for purposes of meeting personal needs related to fish farming, such as inquiring about markets for fish. As, Mpiima et al., (2019) observed, mobile phones empower women and promote joint involvement in agricultural activities that were previously for either men or women alone. With individual ownership of mobile phones, women have the opportunity to tune into any of the various radio 
programmes thereby increasing their agency of preferred listenership and contribute to the spread of information among household members without disrupting the execution of productive roles. As Nzonzo and Mogambi (2016), Mulugeta and Akalu (2017) observe, appropriate policy intervention is necessary for increasing usage of ICTs in agriculture.

Figure 1 shows the distribution of respondents using ICTs to access extension services on fish farming. As earlier alluded to, usage of ICTs to access information on fish farming participation in increasing access to extension services.

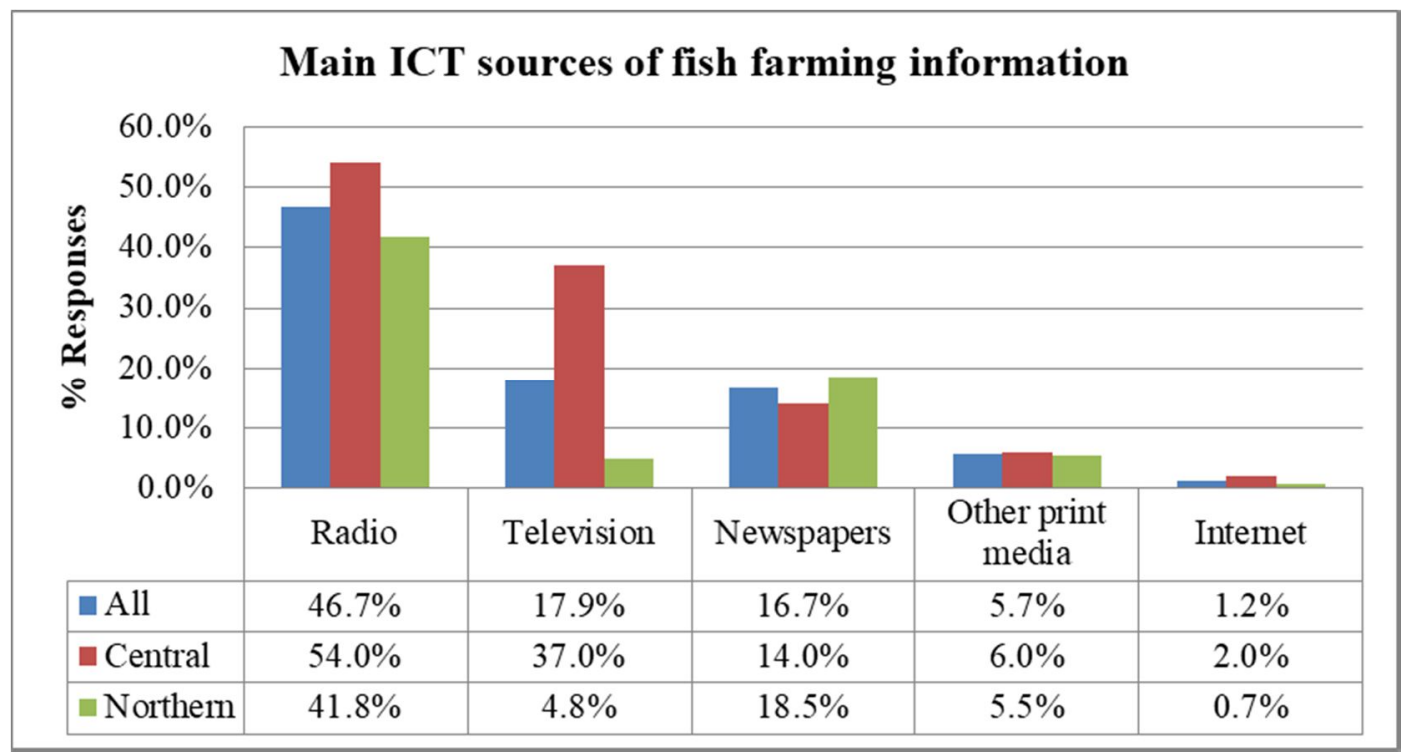

Figure 1. Respondents’ Major ICT Sources of Information on Fish Farming by Region

Radio remains a major source of information on agriculture, and fish farming in particular followed by television. The information was mainly broadcast in English as well as the two main local languages in the study area, namely Luganda for central and Luo for northern region. The study found a statistically significant difference $(\mathrm{P}<0.05)$ in use of radio to access information on fish farming across the two regions. More respondents in the central $(54.0 \%)$ tuned in to programmes on fish farming compared to 41.8 per cent respondents in northern region. Key informant respondents in selected broadcasting stations and extension personnel mentioned that the choice of programme to air on radio is often a joint decision between the producer and presenter, but with limited participation of the target audience, other than during the phone-in session. Furthermore, the use of radio app on mobile phones as opposed to household sets enables listeners to access information at will, and without the worry about conflicting interests with other household members over preferred channels. Moreover, use of household radio sets has gender dynamics and power relations that offer the household head, often a male and owner of the asset, the privilege to tune into channels of his choice. Ownership of mobile phones therefore is important since it breaks the gender barriers and offer women the opportunity to tune in to the desired farming programmes.

Television was the second most frequently used ICT in disseminating information on fish farming. However, only 17 per cent of respondents reported obtaining information on fish farming. The study found a statistically significant difference $(\mathrm{P}<0.05)$ in use of TV to access 
information on fish farming across the two regions. More respondents in the central (37.0\%) obtained information on fish farming compared to 4.8 per cent respondents in northern region. Bukedde television channel broadcasts programmes exclusively in Luganda. The respondents found the audio-visual demonstrations and explanations more informative and easier to follow. Compared to radio, the relatively low access to information via television was due to the high cost of the sets and limited coverage of electricity in the study area. The use of television in disseminating extension messages remains unfeasible for rural farmers, though some of the Key Informant respondents reiterated the need to equip District Fisheries Offices with kits that can periodically be used to air demonstrations to small groups of fish farmers. A further suggestion was to prepare short but comprehensive clips that can be uploaded on to farmers' phones for use in a shared arrangement among much smaller groups of farmers. Such a strategy leverages on the compatibility advantage of television and mobile phones to achieve planned extension objectives.

Comparison of the results from central and northern regions showed a significant difference $(\mathrm{P}<0.05)$ in access to information on fish farming via television. Sixty one per cent respondents in central region reported obtaining fish farming information via TV, compared to 15.1 per cent in northern region. Since Bukedde television is based in central region, and airs programmes in Luganda, the fish farmers in the region have the privilege to listen to 'Enkumbi telimba', a Luganda idiom meaning 'farming is a gainful venture'. The programme is broadcast weekly and provides information on success stories about the benefits of applying good farming practices. In addition, there was Central Broadcasting Corporation (CBS) TV, that is locally based in central region and transmitting information in the local language, Luganda. For the respondents in the northern region, the results showed that less than 5 per cent did not receive information on fish farming via television. The limited access to information on fish farming can be partly attributed to the absence of a locally-based television channel. Even though television may favour urban areas compared to rural areas due to availability of electricity, special meetings can be arranged, and socially agreed upon for the fish farmers to view the programmes.

Newspapers were not frequently accessed for obtaining information on fish farming. While the daily New Vision devoted Friday to general farming news, only few articles on fish farming appeared compared to crops and livestock production. For example, in 2018, there were 8 $(8.2 \%)$ articles on fish farming in the New Vision compared to $50(51.0 \%)$ on crops and livestock production. In addition, 40 (40.8\%) articles focused on general agriculture topics. For the major local languages spoken in the study area, Bukedde, a Luganda daily newspaper published articles on farming every Monday while articles in Luo appeared in the weekly Rupiny. Similarly, information on fish farming was much lower in local newspapers. Generally, the results obtained from a review of the newspapers demonstrate underutilisation of the newspapers in disseminating information on fish farming, which ultimately limits accessibility.

Despite limited availability of information on fish farming in the newspapers, low literacy levels and unaffordable costs were constraining factors among some of the fish farmers. The farmer group approach can however be used to access to information from newspapers and other print media. Farmer groups can be an important avenue for awareness creation about the availability of the farming news as well as increasing access and readership. Ultimately, such group efforts harness social capital development and strengthening needed to achieve wider benefits of shared learning. Alongside newspaper articles, researchers and extension officials need to ensure production of simple written messages in form of booklets that can be accessed and utilised by fish farmers. Print materials are a good source of information given that they can be referred to at the convenience of the farmers. Moreover, as levels of education increase 
amidst advancements in ICTs, internet and smart phones further present opportunities for effective utilisation of print materials.

Amidst an array of sources of information from the various ICTs is the question of relevance and usefulness of information transmitted. The preparation and delivery of the information is often predetermined by the guest presenters with limited or no participation of the users, rendering the approach top-down and non-participatory. It is for this reason that half of the respondents who obtained information from the ICT sources underrated the usefulness of the information. Inability to apply extension information was partly attributed to lack of follow-up visits to demonstrate use and application of technologies. These results conform to literature on communication which accentuates the complementarities of mass media and interpersonal channels in the adoption of innovations. Rogers (2003:205) observes that among other strengths, mass media enables creation of knowledge and spread of information, while interpersonal channels are best at securing clarification or additional information about an innovation. In order to achieve effectiveness in communication of agricultural technologies and information, extension needs to balance the use of mass media and interpersonal channels. Key Informant interviews with extension actors and presenters of information broadcast on radio and television affirmed that follow-up visits to fish farms can increase uptake of information through provision of practical advice to farmers.

The study indicated that farmers who obtain information from mass media channels such as radio and television often consulted extension workers for clarifications or on requests for practical guidance about on-farm activities such as sampling. The importance of these findings is the synergies that different extension methods can yield. Farmers who live within close proximity of extension workers' offices utilised the opportunity to request and receive on farm visits. The extension workers confirmed that such farmers received more visits since the cost of travel was low. The respondents further indicated that such visits were more beneficial as they met the identified needs. The findings support the demand-driven extension debates espoused. It is important to closely observe and listen to the actors about what methods seem to work better or not. As a way of tapping benefits of synergies, Kumaran et al., (2012) propose an extension methodology that includes all three (individual, group and mass) contact methods in proper proportion according to the nature of the message and clients. Evidence drawn from the study shows the importance of farmers' involvement in extension. Whether as individuals or groups, farmers' face to face interactions as well as use of ICTs can accelerate diffusion of innovations, services and information. Moreover, farmers view themselves as possessing agency to guide and influence provision of extension services.

The lack of exposure to novel knowledge on aquaculture by extension staff was a major concern of the respondents, and a precarious gap in Uganda's extension system. The Fisheries extension staff in the districts reiterated the need for refresher courses to keep abreast with technological advancements in aquaculture information needed to increase productivity, and to align extension work with agriculture sector policies. They noted absence of formally organised training courses initiated by NARO or MAAIF. The extension workers expressed concerns about having limited knowledge in particular aspects of fish farming as one fisheries officer commented:

Some fish farmers are increasingly orienting themselves to commercial production techniques that require higher level of inputs. Among such inputs include complete diet factory manufactured fish feeds, sex reversed all-male tilapia fingerlings that grow faster and, equipment for cage fish culture. The farmers expect us to give them technical guidance but we are not very equipped with this knowledge. MAAIF headquarters need to financially 
support us to undertake relevant short training courses because the districts do not have sufficient budgets to cover such courses (KI respondent, Kalungu district).

The concerns raised in the respondent's comment shows that continued training for extension staff is important for building skills and confidence needed to achieve effectiveness in meeting needs of farmers. Other scholars (Kumaran et al., (2012), Hailua et al., (2020) document the need to provide refresher training courses for extension workers so as to meet the needs of farmers.

\section{Model for improving provision and access to extension services}

In-depth discussions with fish farmers revealed their 'lived-worlds' experiences in accessing extension services. Joint discussions to reflect on social interactions with extension workers resulted in agreed suggestions on how to improve access to extension services. The discussions culminated into a proposed structured schedule shown in Figure 2. The diagram reflects the key duties performed by government extension workers based at a Sub-county, the second lower administrative local government level after a District. Among the duties of a Sub-county aquaculture extension worker include visits to individual farms, training farmers, attending to farmers' information needs and requests, consultations with relevant authorities at local and national level and desk work for general planning and reporting of extension activities.

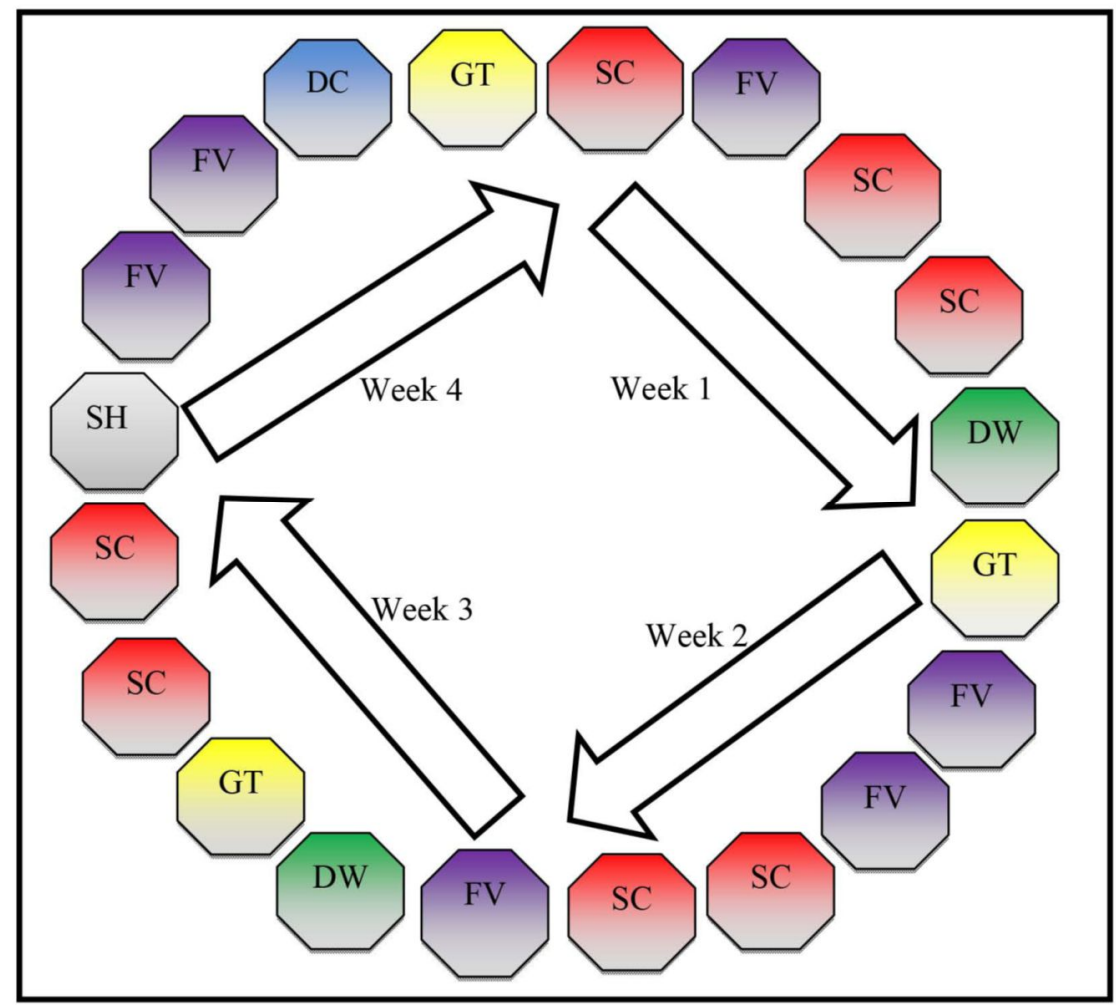

KEY: FV = Farm visits to individual fish farmers; GT = Farmer-group training; $\mathrm{SC}=$ Sub-county office consultations by fish farmers; DC = District consultation/ reporting by Sub-county Aquaculture extension staff; $\mathrm{SH}=$ Stakeholder consultations by Sub-county Aquaculture Extension staff; DW = Desk work

Figure 2. Preferred Work Schedule for the Sub-county-based Extension Staff 
The diagram depicts a participatory and localised extension approach that can be used to assess extension needs from various actors and ultimately cause execution of appropriate actions. This approach helps to identify and address specific individual and common needs of farmers. Tackling specific expressed needs of farmers is important, as the generic information provided may be irrelevant to the farmer's location. One of the fundamental issues underlying the idea of an extension work schedule is the distant locations of the fish farming households. Households involved in fish farming are sparsely located, often in areas with poor road infrastructure amidst limited transport and other resources for effective extension work. A socially agreed strategy between extension workers and the fish farmers is necessary to navigate through such constraints to carry out obligatory extension duties.

Notably, such a farmer-centred extension approach can nurture closer and regular interface with 'life worlds' of farmers and other actors for deeper understanding of their needs and possible solutions. In addition, extension workers need to create time for linkages and consultations with researchers about novel research findings. Such linkages are important for knowledge sharing about farmers' extension needs and possible research-based solutions. The schedule therefore provides an important signal for extension workers to interact with relevant stakeholders for information on new developments in their field. In a nutshell, the schedule is a means to improve extension worker-farmer interactions, promote farmer empowerment, and increase access to aquaculture information and technologies. Once adopted, the schedule will narrow the prevailing information and action gaps between fish farmers and extension workers in the country.

\section{Conclusion}

Socio-economic characteristics of fish farmers, particularly land, income from fish and membership to fish farmer groups have a relationship with extension visits. In a number of instances, households with large size of land often had suitable sites that enabled establishment of ponds. Similarly, households that earned income from fish attracted extension workers for purposes of recording and reporting successful ventures. While an understanding of such relationships may promote useful extension activities, extension workers need to cautiously carry out their work without compromising equity values. Increasing access to extension services by small, medium and large fish farmers should be the target of extension workers. There is a need for extension service providers to specifically pay attention to small holders by establishing linkages with larger scale fish farmers. Such linkages can include bulking fish for sale to identified niche markets.

The relationship between membership to fish farmer groups and extension service provision revealed the importance of social organisation in promoting desired actions. In particular, there is need to re-orient the farmer group approach to suit the unique situations of fish farmers by targeting a wider geographical area beyond a village. The limited use of group approaches denies fish farmers the opportunity to tap the fundamental social values and benefits that groups offer. Extension actors should provide technical advice on forming socially sustainable fish farmer organisations to improve access to extension services.

Demand for extension services is fundamental for aligning services with needs. As extension workers advocate for consultations from fish farmers, there is need for prompt and effective response to the concerns farmers raise. However, the prevailing low extension staff levels hinder adequate and timely responses to farmers' demands. Besides increasing staff capacity, 
government needs to implement policy provision on formalising private extension service providers. There is a need to encourage demand-driven extension approach because of its potential to match needs and services. Effective demand can be achieved and sustained if supply-responses are readily available and known to farmers. The District Fisheries Officers should continuously identify pressing farmers' needs and accordingly organise training and other extension activities.

The article noted low usage of ICTs in extension due to absence of clearly planned information packages. Extension workers should use all possible avenues to explore available synergies and lobby for incorporation of fish farming materials into various mass media ICTs. Use of radio and TV for dissemination of information on fish farming should ensure prior advertisement to alert listeners about the timing of the programmes. While almost all the respondents owned mobile phones, their usage in accessing specific fish farming extension information was rare. There is a need for research and extension bodies to design appropriate messages that can be transmitted via mobile phones.

Lastly, the paper has showed that increasing access to extension services for fish farmers requires an understanding of the farmers' characteristics and extension needs. In particular, the uniqueness of pond aquaculture characterized by widely located households requires innovative socially negotiated approaches. Helping fish farmer, particularly small holders to join groups can increase access to extension services. Moreover, group approach is beneficial to both the extension worker and the farmer. On the part of the extension worker, group approach maximizes time usage by providing specific services to many farmers as opposed to costly individual farm visits. As for the fish farmers, group approach enables sharing of knowledge, mutual agreement on the extension schedule and provision of feedback to the extension workers. Hence, the article fronts a farmer centred model deemed feasible for increasing access to extension services. Extension workers should use the model, and together with fish farmers take note of any aspects that may require adjustment to suit the prevailing situations. Such farmer-level strategies require availing opportunities for increased extension farmer interactions. Extension workers should therefore guide formation of fish farmer groups, and cautiously ensure enrolment of large and smallholder men and women. Specifically for the northern region, there is a need for the Fisheries Extension Officer to identify and respond to the extension needs of fish farmers through various means including ICTs so as to increase production and profits from their fish farming enterprises. The lessons drawn from this study should be applied to improve extension service provision among fish farmers in Uganda.

\section{Acknowledgement}

Support provided by the World Bank and Government of Uganda via the National Agricultural Research Organization (NARO) under the Agricultural Technology, Advisory and Agribusiness Services (ATAAS) program is acknowledged. We thank the respondents for availing data for the study.

\section{References}

Aanyu, M., Opio, D., Aruho, C. and Atukunda, G., 2020. Potential for enhancing and sustaining commercial aquaculture in Uganda: Producer organizations, contract farming schemes and public-private partnerships." International Journal of Fisheries and Aquatic Studies 8(2): 258-264. 
Abdallah, A. and Abdul-Rahaman, A., 2016. "Determinants of Access to Agricultural Extension Services: Evidence from Smallholder Rural Women in Northern Ghana." Asian Journal of Agricultural Extension, Economics \& Sociology 9(3): 1-8.

Adong, A., Mwaura, F. and Okoboi, G., 2013. "What Factors Determine Membership to Farmer Groups in Uganda? Evidence from the Uganda Census of Agriculture 2008/9." Journal of Sustainable Development 6(4):37-55.

AfranaaKwapong, N. and Nkonya E., 2015. "Agricultural Extension Reforms and Development in Uganda." Journal of Agricultural Extension and Rural Development 7(4):122-134. Ahuja, R., 2011. Research Methods. India: Prem Rawat.

Ali-Olubandwa, M. A., Kathuri, N.J. and Wesonga, T.E.O., 2011. "Effective Extension Methods for Increased Food Production in Kakamega District." Journal of Agricultural Extension and Rural Development 3(5):95-101.

Atukunda, G, State, A.E., Molnar, J. and Atekyereza., P., 2018. “Aquaculture Development and Uganda's Agricultural Extension System: The Case of Fish Farmers in Central and Northern Uganda." Journal of Fisheries and Aquaculture Development 137.1-11.

Azumah B. S., Donkoh, S.A. and Awuni, J.A., 2018. "The Perceived Effectiveness of Agricultural Technology Transfer Methods: Evidence from Rice Farmers in Northern Ghana." Cogent Food and Agriculture 4:1, 1503798.

Bryman, A., 2006. "Integrating Quantitative and Qualitative Research: How is it done?" Qualitative Research 6(97):97-113.

Bryman, A., 2007. "Barriers to Integrating Quantitative and Qualitative Research." Journal of Mixed Methods Research 1(8):8-22.

Creswell, W. J., Klassen, A.C., Plano, V.L. and. Smith, C., 2011. Best Practices for Mixed Methods Research in Health Sciences. Office of Behavioural and Social Sciences Research, National Institute of Health.

David, S. and Asamoah, C., 2011. "Video as a tool for agricultural extension in Africa: a case study from Ghana." International Journal of Education and Development using Information and Communication Technology 7(1):26-41.

Ejiogu-Okereke, N. E., Chikaire, U.J., Ogueri, I.E. and Chikezie, P.N., 2016. "Roles of Information and Communications Technologies in Improving Fish Farming and Production in Rivers State, Nigeria.” Library Philosophy and Practice (e-journal). 1445.

Ekou, J. and Alungat, A., 2015. "Increasing Agricultural Production and Productivity among Smallholder Farmers in Uganda through Agricultural Extension." Scholars Journal of Agriculture and Veterinary Sciences 2(2B):120-124.

Faure, G., Desjeux, Y. and Gasselin. P., 2012. "New Challenges in Agricultural Advisory Services from a Research Perspective: A Literature Review, Synthesis and Research Agenda." The Journal of Agricultural Education and Extension 18(5):461-492. DOI: 10.1080/1389224X.2012.707063.

Food and Agricultural Organisation (FAO). 2010. The State of World Fisheries and Aquaculture, 2010. FAO, United Nations, Rome.

Food and Agricultural Organisation (FAO). 2017. Extension for Aquaculture Development Committee on Fisheries: Sub-committee on Aquaculture 9th session, 24-27 October 2017.

Food and Agricultural Organisation (FAO). 2019. Agricultural Extension Manual. FAO, United Nations, Rome.

Food and Agricultural Organisation (FAO). 2020a. FAO Yearbook. Fishery and Aquaculture Statistics 2018. Rome. https://doi.org/10.4060/cb1213t.

Food and Agricultural Organisation (FAO). 2020b. The State of World Fisheries and Aquaculture, 2012. Sustainability in Action. FAO, United Nations, Rome. 
FAO. 2007-2020. Fishery and Aquaculture Country Profiles. Nigeria. Country Profile Fact Sheets. In: FAO Fisheries and Aquaculture Department [online]. Rome: FAO. Updated 1 November 2017 [Cited 25 May 2020]. http://www.fao.org/fishery/.

FAO. 2004-2020. Fishery and Aquaculture Country Profiles. Uganda (2004). Country Profile Fact Sheets. In: FAO Fisheries and Aquaculture Department [online]. Rome: FAO. Updated 1 December 2004 [Cited 25 May 2020]. http://www.fao.org/fishery/.

Freeman, K., and Mubichi. F., 2017. "ICT Use by Smallholder Farmers in Rural Mozambique: A Case Study of Two Villages in Central Mozambique." Journal of Rural Social Science 32(2):119.

Gido, O.E, Sibiko, K.W., Ayuya. O.I. and Mwangi. J.K., 2014. "Demand for Agricultural Extension Services among Small-Scale Maize Farmers: Micro-Level Evidence from Kenya." The Journal of Agricultural Education and Extension. DOI: 10.1080/1389224X.2013.872045

Government of Uganda, 2020. Uganda Vision 2040.

Hailemichael, S. and Haug, R. 2020. "The Use and Abuse of the 'Model farmer' Approach in Agricultural Extension in Ethiopia." The Journal of Agricultural Education and Extension. DOI: 10.1080/1389224X.2020.1757475.

Hailua, M., Tolossab, D., Kassac, B. and Girmad, A., 2020. "Understanding Factors Affecting the Performance of Agricultural Extension System in Ethiopia." Ethiopian Journal of Agricultural Science 30(4): 237-263.

Hyuha, S. T., Bukenya, O.J., Twinamasiko, J. and Molnar, J., 2011. "Profitability Analysis of Small Scale Aquaculture Enterprises in Central Uganda." International Journal of Fisheries and Aquaculture 2(15):271-278.

Kasozi, N., Degu, D., Opie, H., Ejua, P., Atibuni, K., and Mukalazi. J., 2014. “Assessment of the Socio-economic Value of Aquaculture in the West-Nile Agro Ecological Zone of Uganda." World Journal of Fish and Marine Sciences 6(3):245-251.

Kassem S. H., Shabana, R.M., Ghoneim, A.Y. and Alotaibi, M.B., 2019. "Farmers' Perception of the Quality of Mobile-based Extension Services in Egypt: A comparison between public and private provision." Information Development 36(2):161-180.

Kish, L., 1965. Survey Sampling. New York: John Willey and Sons, Inc.

Kothari, C.R and Garg, G., 2014. Research Methodology: Methods and Techniques. $3^{\text {rd }}$ Edition. India: New Age International Publishers.

Kumaran, M., Vimala, D.D., Chandrasekaran, V.S., Alagappan, M. and Raja, S., 2012. "Extension Approach for an Effective Fisheries and Aquaculture Extension Service in India." The Journal of Agricultural Education and Extension 18(3):247-267.

Long, N., 2001. Development Sociology: Actor Perspectives. London: Routledge.

Lukuyu, B., Place, F., Franzel, S. and Kiptot, E., 2012. "Disseminating Improved Practices: Are Volunteer Farmer Trainers Effective?” The Journal of Agricultural Extension and Education 18(5):525-540.

Martin, B. L. and Abbott, A. 2011. "Mobile Phones and Rural Livelihoods: Diffusion, Uses, and Perceived Impacts among Farmers in Rural Uganda." Information Technologies \& International Development 7(4):17-34.

Ministry of Agriculture Animal Industry and Fisheries (MAAIF). 2013. National Agriculture Policy. Entebbe, Uganda.

Ministry of Agriculture Animal Industry and Fisheries (MAAIF). 2016a. The National Agricultural Extension Policy. Entebbe, Uganda.

Ministry of Agriculture Animal Industry and Fisheries (MAAIF). 2016b. The National Agricultural Extension Strategy 2016/17-2020/21. Knowledge Driven Agricultural Revolution. Entebbe, Uganda. 
Ministry of Agriculture Animal Industry and Fisheries (MAAIF). 2016c. Agriculture Sector Strategic Plan. 2015/16-2019/20.

Ministry of Agriculture Animal Industry and Fisheries (MAAIF). 2018. The National Fisheries and Aquaculture Policy. Entebbe, Uganda.

Ministry of Agriculture Animal Industry and Fisheries (MAAIF). 2019. National Aquaculture Development Strategy and Action Plan of Uganda: 2020-2025. MAAIF Entebbe, Uganda.

Mpiima, M. D., Manyire, H., Kabonesa, C., and Espiling, M., 2019. “Crop Production, Gender Roles and the Use of Mobile Phones and Radios for Agricultural Information by Farmers in Apac District, Northern Uganda." Open Journal of Social Sciences 7, 89-111.

Mugabi, N., State, E. A., Omona, J., Jansson, B., 2018. "Revolutionising Agriculture Extension Delivery through Mobile Telephony: The experience of Village Enterprise Agent Model in greater Masaka Area, Uganda." Sustainable Development and Planning X 963.

Mulugeta, T. and Akalu, D. 2017. "Review on Potential of Mobile Phone Usage in Agricultural Information Dissemination in Ethiopia." International Journal of Scientific and Research Publications 7(12):63-75.

Muyanga, M. and Jayne, T.S., 2008. "Private Agricultural Extension System in Kenya: Practice and Policy Lessons." The Journal of Agricultural Education and Extension 14(2):101-124.

Mwaura, F., 2014. "Effect of Farmer Group Membership on Agricultural Technology Adoption and Crop Productivity in Uganda." African Crop Science Journal 22(s4):917927.

National Planning Authority (NPA) 2020. Third National Development Plan (NDP III) 2020/21 - 2024/25. National Planning Authority, Uganda.

Ndibongo-Traub, L. and Jayne, R., 2018. "Towards Agricultural Transformation: Factors Influencing the Cultivation of High Value Agricultural Products in Uganda." Conference Paper Presented at the Agricultural Economics Association of South Africa, September 2527, Cape Town South Africa.

Norton, W. and Alwang, J., 2020. "Changes in Agricultural Extension and Implications for Farmer Adoption of New Practices Changes in Agricultural Extension and Implications for Farmer Adoption of New Practices." Applied Economic Perspectives and Policy 42 (1):8-20.

Nzonzo, D. and Mogambi, H., 2016. "An Analysis of Communication and Information Communication Technologies Adoption in Irrigated Rice Production in Kenya." International Journal of Education and Research 4(12):295-316.

Obiero, O. K., Waidbacher, H., Nyawanda, O.B., M. Munguti, M.J., Manyala, O.J. and KaundaArara, B., 2019. "Predicting Uptake of Aquaculture Technologies among Smallholder Fish Farmers in Kenya." Aquaculture International 27:1688-17067.

Rogers, E., 2003. Diffusion of Innovations. $5^{\text {th }}$ Edition. New York: The Free Press.

Rugema, S., Sseguya, H. and Kibwika, P., 2018. "Determinants of Smallholder Farmers' Participation Rice Value Chain in Uganda." Journal of Agricultural Extension 2(22):62-71.

Suvedi, M., Ghimire, R. and Kaplowitz, M., 2017. "Farmers' Participation in Extension Programs and Technology Adoption in Rural Nepal: a Logistic Regression Analysis.” The Journal of Agricultural Education and Extension. DOI:10.1080/1389224X.2017.1323653

Taye, H., 2013. "Evaluating the Impact of Agricultural Extension Programmes in Sub-Saharan Africa: Challenges and prospects." African Evaluation Journal 1(1):1-9.

Tibihika D.M.P., 2014. "Fish Farming Dynamics in South Western Highlands Agro-Ecological Zone: Baseline survey in Kabale, Kisoro, Rukungiri and Kanungu Districts." International Journal of Fisheries and Aquatic Studies 1(5): 182-205.

Uganda Bureau of Statistics (UBOS). 2011. Uganda Census of Agriculture (UCA) 2008/09 at a Glance. UBOS, Kampala. 
Uganda Bureau of Statistics (UBOS). 2019. 2019 Statistical Abstract. UBOS Kampala, Uganda. Uganda Bureau of Statistics (UBOS). 2020. The Annual Agriculture Survey 2018. Statistical Release 2020. UBOS Kampala, Uganda.

Uganda Communications Commission (UCC). 2019. State of Information Communications Technology (ICT) for Agricultural Innovations in Uganda 2019.

Vanclay, F., 2004. "Social Principles for Agricultural Extension to Assist in the Promotion of Natural Resource Management." Australian Journal of Experimental Agriculture 44: 213-222.

Wellard, K., Rafanomezana, J., Nyirenda, M., Okotel, M. and Subbey, V., 2013. "A Review of Community Extension Approaches to Innovation for Improved Livelihoods in Ghana, Uganda and Malawi." The Journal of Agricultural Education and Extension 19(1):21-35. 